\title{
Passing on the Hot Potato: Lessons from a Policy Brief Experiment
}

\author{
Penelope Beynon, Marie Gaarder, Christelle Chapoy and \\ Edoardo Masset
}

\begin{abstract}
Research has potential to improve the lives of the world's vulnerable people - if it is appropriately referred to in decision-making processes. While there is a significant industry of activity each year to communicate research findings, little systematic research has tested or compared the effectiveness of such efforts. One popular research communication tool is the policy brief. In this article we draw on findings from a recent study on how a policy brief works; concluding that a policy brief does not have a linear effect on its readers. Instead, a reader can take a number of alternative routes from belief to action, some of which could subvert the intended outcome of the policy brief in question. We reflect also on the question of what makes for an effective policy brief; concluding that policy briefs that give personality and form to the researcher behind the written word may invoke a deeper relationship between the reader and the author, and affect a greater inclination in the reader to share the message with someone else - that is, they pass the hot potato. ${ }^{1}$ The study itself was a first of its kind and contributes to our understanding about the effectiveness of research communication, as well as how to evaluate research communication effectiveness.
\end{abstract}

\section{What is a policy brief and why bother to study it?}

A policy brief is a concise standalone document that prioritises a specific policy issue and presents the evidence in a non-technical and jargon-free language. ${ }^{2}$ In general, the purpose of a policy brief is to distil or to synthesise evidence with the intention of influencing the thinking and actions of policy actors as they take decisions in complex policy processes. That is, to achieve the elusive outcome of evidence-informed policymaking. ${ }^{3}$ Many funders require research organisations to produce succinct summaries of research findings in a 'user-friendly format' to ensure that funded research is disseminated and understood by target audiences. For decades, policy briefs have dominated as the format of choice for both scholarly and advocacy-based organisations seeking to influence policymakers.

The value and effectiveness of policy briefs for influencing policy outcomes is disputed. In a 2008 study, the Overseas Development Institute (ODI) and the Science and Development Network (SciDev.Net) interviewed a sample of policymakers from developing and developed countries and reported that while 50 per cent of policymakers and 65 per cent of researchers think that dissemination of research findings is not sufficient to have an impact on policy, 79 per cent do think that policy briefs are valuable communications tools (Jones and Walsh 2008). The findings of the ODI-SciDev.net study have been contested due to the leading nature of some of the questions that were fielded and some other studies have posited differing results. In particular, a policy community survey commissioned by the International Development Research Centre (IDRC)'s Thank Tank Initiative and carried out across Africa, Latin America and Asia finds policy briefs to be among the least useful forms of information exchange to support respondents' work in national policy. The study shows that informal communications, such as newsletters and online forums, are considered less useful than user-driven, self-directed information exchanges such as statistical databanks, online publications and reports. In-person events and advice from individual experts were also considered more useful than briefs and bulletins (Cottle 2011). 


\begin{tabular}{|c|c|c|}
\hline Group & Treatment & Purpose \\
\hline Treatment group 1 & $\begin{array}{l}\text { A basic } 3 \text {-page brief based on the } \\
\text { systematic review }\end{array}$ & $\begin{array}{l}\text { Allowed us to test for an effect } \\
\text { achieved by providing basic } \\
\text { information }\end{array}$ \\
\hline Treatment group 2 & $\begin{array}{l}\text { The same basic 3-page brief based on } \\
\text { the systematic review PLUS an opinion } \\
\text { piece credited to a sector expert and } \\
\text { co-author of the original systematic } \\
\text { review }\end{array}$ & $\begin{array}{l}\text { Allowed us to test for an effect } \\
\text { achieved by providing an opinion } \\
\text { from an authority source }\end{array}$ \\
\hline Treatment group 3 & $\begin{array}{l}\text { The same basic 3-page brief with the } \\
\text { same opinion piece, this time credited } \\
\text { to an unnamed IDS Research Fellow }\end{array}$ & $\begin{array}{l}\text { Allowed us to test for an effect } \\
\text { achieved by providing an opinion in } \\
\text { the absence of a suggestion of } \\
\text { authority }\end{array}$ \\
\hline Control group & $\begin{array}{l}\text { A placebo policy brief }{ }^{6}-\text { a different } \\
\text { 2-page brief on a distantly related } \\
\text { topic }\end{array}$ & $\begin{array}{l}\text { Allowed us to control for survey } \\
\text { effects and other unanticipated } \\
\text { changes that might influence } \\
\text { knowledge or actions during the study } \\
\text { period }\end{array}$ \\
\hline
\end{tabular}

A lesson emerging from these and other recent studies is that policy briefs are useful when policy interest exists, capacity is there to absorb, timing and context are favourable, the message and conclusions are clear, and when the brief is but one of the information and exchange tools used.

But despite their proliferation in recent decades, ${ }^{4}$ the likely substantial amount of time and money invested in developing policy briefs each year ${ }^{5}$ and the debates as to their worth, very little serious research has been undertaken to explore the mechanism through which they work or to test their value in changing beliefs and prompting actions. We developed a study to do just that.

\section{A sledgehammer to crack a nut? A multi- armed randomised controlled trial}

From June to December 2011, IDS conducted a study in collaboration with the International Initiative for Impact Evaluation (3ie) and the Norwegian Agency for Development Cooperation (NORAD) that sought to explore what difference a policy brief makes top readers' beliefs and actions, and whether different formats of a policy brief achieve different effects.

There is much to say about the study methods, and full details are published in the full study report What Difference does a Policy Brief Make? (Beynon et al. 2012). In brief, the study was complex; it used a multi-arm randomised controlled design to compare the beliefs and actions of three treatment groups and a control group at four points in time. Multi-arm designs compare a number of experimental treatments to a common control arm. In the case of our study, the three treatments were different versions of a policy brief, each of which summarised findings from a systematic review undertaken by Masset et al. in 2011 and which dealt with agriculture interventions and their effects on nutritional status of children.

The different versions of the brief used different techniques for engaging the reader; techniques that sought to give personality and form to a researcher behind the written words. In particular, the different versions of the brief explored Opinion and Authority, two key ingredients for effective policy briefs recommended by Jones and Walsh in the 2008 international study of policymakers. Opinion refers to the views of a researcher, and Authority refers to the credibility of the source of information. Specifically, the study participants were randomly allocated to one of four groups and received one of four policy briefs as detailed in Table 1.

The main data collection tool was a series of four surveys that sought to measure changes in participants' beliefs and reported actions 
Figure 1 Data collection points and methods

\section{1 week before intervention \\ - Baseline survey of beliefs}

\author{
Day of \\ intervention \\ - Follow-up survey \\ of immediate \\ changes to beliefs \\ and intentions to \\ act
}

\begin{tabular}{|c|c|c|c|}
\hline \multicolumn{2}{|c|}{$\begin{array}{l}1 \text { week post } \\
\text { intervention }\end{array}$} & \multicolumn{2}{|c|}{$\begin{array}{l}3 \text { months post } \\
\text { intervention }\end{array}$} \\
\hline$\bullet$ & $\begin{array}{l}\text { Follow-up survey } \\
\text { of short-term } \\
\text { changes to beliefs, } \\
\text { short-term } \\
\text { completed actions } \\
\text { and short-term } \\
\text { intentions to act } \\
\text { Qualitative } \\
\text { interviews with a } \\
\text { sample of } \\
\text { respondents to } \\
\text { interrogate drivers } \\
\text { for attrition }\end{array}$ & • & $\begin{array}{l}\text { Follow-up survey } \\
\text { of longer-term } \\
\text { changes to beliefs } \\
\text { and longer-term } \\
\text { completed actions } \\
\text { Qualitative } \\
\text { interviews with a } \\
\text { sample of } \\
\text { respondents to } \\
\text { gather examples of } \\
\text { outcomes in } 4 \\
\text { areas hypothesised } \\
\text { for the study }\end{array}$ \\
\hline
\end{tabular}

mean that other policy briefs will have greater or lesser effect. Despite these limitations, the study itself is a first of its kind for development-related research communication and contributes to our understanding about the effectiveness of research communication as well as how to evaluate research communication effectiveness.

In this article we report two key findings of the study, and discuss their implications for our understandings about how a policy brief works, and about what makes for an effective policy brief.

On the surface, finding that a significant proportion of participants pass on the message of the policy brief would appear to be a good outcome for research communication - this activity would (a) keep messages in circulation, thus increasing the chance they would land on the right desk at the right time to influence the right decision-making process, and (b) add currency to the messages as they are brokered from a trusted source, thus increasing the chance they will be read by the receiver.

However, a thematic analysis of participants' responses to the question 'In your own words what was the key message of the brief?' showed readers took away many and varied messages: some in keeping with the key messages of the brief (e.g. that bio-fortification is promising but not proven), some contrary to the key messages of the brief (e.g. that bio-fortification is a proven solution), some very generic messages incidental to the systematic review (e.g. that child nutrition is a problem) and some that lead us to question whether the respondent read the brief at all aware of other study limitations. In particular, attrition was high (although fairly uniform across groups) and the nature of the treatment may well 
Finding 1 The policy brief has a weak effect on beliefs but prompts readers to pass on the hot potato

Overall, our study found the policy brief had a fairly weak effect on readers' beliefs; creating more evidence-accurate beliefs where no priors were held, but only slightly affecting those who entered the study with prior beliefs.

However, the study also found readers in all of the groups reported high rates of information sharing. For the most part, participants shared the information because they thought the content would be of general interest to networks of peers with whom they frequently share information, or of specific interest to particular individuals whose study or work is directly linked to agriculture or nutrition, the topic of the brief. ${ }^{8}$ For example:

- One respondent shared the policy brief with an email list of colleagues who completed their Masters course in natural resource assets and management together. He usually forwards information to this email list and thought it would be of general interest to them.

- Another shared the policy brief with one of her clients, a country coordinator of an organisation that breeds and disseminates vitamin A fortified maize. She shared it with her client because 'she thought it was interesting and had direct relevance to what they were doing'.

- A third respondent reported sharing the policy brief with his brother who is a nutritionist.

(e.g. directly quoting the first line of the brief 'Agriculture interventions alone will not eradicate malnutrition').

Therefore, when coupled with a limited effect on belief, information sharing gives us pause for thought; it means that readers do move directly from receiving evidence to taking action, either without engaging with that evidence at all (i.e. without reading it) or with engagement but without an updated set of beliefs.

Participants told us they shared information by email or in person. One respondent elaborated that while she regularly disseminates information through formal methods, like a research report or press release, if she feels that it is directly relevant she does it through more informal means, emails and verbal discussions. Whatever the reason for the weak effect that the policy brief has on beliefs, if readers are telling other people about the message without fully understanding it themselves, this could have potentially negative outcomes for the researchers' overall goal. These findings have implications for our understandings about how a policy brief works, which we turn to now.

\section{How does a policy brief work?}

Figure 2 presents a linear model of how a policy brief works. It predicts that a policy brief reaches a reader and prompts him or her to engage with a message; by engaging with the message readers update their knowledge on a topic and create an evidence-accurate belief; these new or reinforced beliefs spark an action commensurate with the reader's role; and depending on the current opportunity for change, some or all of the readers' actions will lead to changes in policies and/or practice that ultimately improve people's lives.

The linear model presented in Figure 2 is certainly overly simplistic. Studies of media communication have focused on the phenomenon that different individuals may receive the same message but act on it quite differently. Influential studies conducted by Carl Hovland throughout his career (e.g. Hovland 1954) concluded that people are very selective in how they use media; in particular regarding exposure, interpretation of information, and retention of information obtained through the media. In particular, three types of selectivity are relevant here:

- selective exposure (whereby people seek out not only topics of interest to them but more importantly viewpoints with which they expect to agree);

- selective perception (whereby people interpret facts to suit their existing biases); and 
Figure $2 \mathrm{~A}$ simple linear model of how a policy brief works

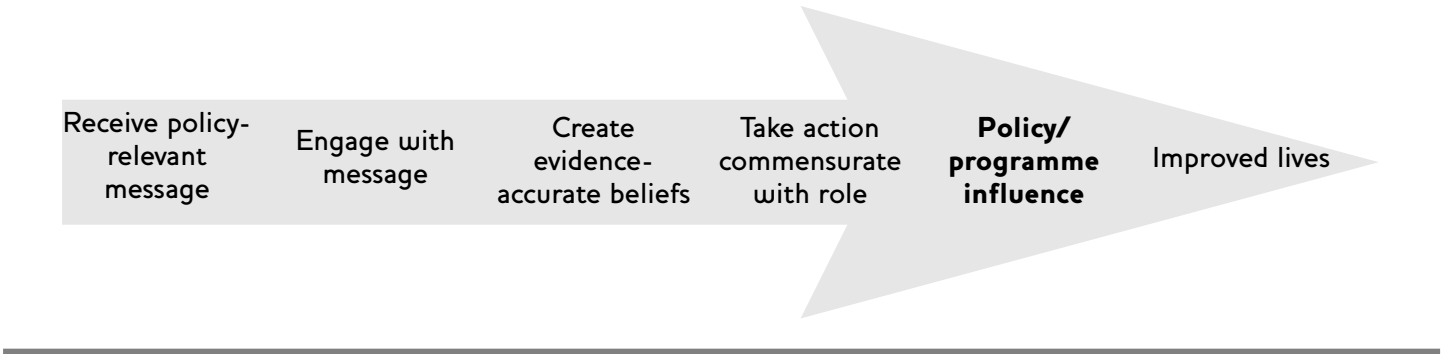

- selective retention (whereby people remember messages that support their opinion longer than they remember opposing messages).

So what would this mean for our simplified model? Firstly, we cannot assume that when readers receive a policy brief they automatically engage with the message by reading the brief. It is far more likely (particularly in this era of information overload) that discerning readers discard a significant amount of information they receive without ever reading it at all based on quick judgements informed by a few features that are immediately apparent (e.g. title, source and whether they find the visual layout pleasing). That is, they exercise selective exposure.

We expect that as self-selecting volunteers, the participants in our own study are probably more likely to have actually read the policy brief treatment they received than an average target audience. In a 'real world' situation, selective exposure presents a challenge for research communication - how can we boost the likelihood that a policy brief will actually be read by the target audience? One approach is to alter the context in which a policy brief is received; making sure at the very least it is received through a trusted source if not as part of a wider engagement strategy. In fact some would argue that a policy brief is never intended to have influence in and of itself and should always be part of a wider engagement strategy. ${ }^{9}$ This may well be the case for key target audiences, but it is inevitable that wider audiences will stumble across policy briefs through their day-to-day activities (either when intentionally seeking information or received spontaneously from networks and communities of practice). For these audiences, we need to make policy briefs engaging at first glance, in the hope of increasing the likelihood that readers will take time to read on.
Secondly, selective perception and selective retention theories suggest that reading is not (necessarily) believing. Depending on the type of prior beliefs a reader holds, it may take repeated evidence before he or she actually updates his/her beliefs to form an evidence-accurate belief, and if it is a firmly held belief (fundamental prior) it may not lead to any update at all. Indeed, evidence suggests that when confronted with evidence that undermines a strongly held opinion (a 'fundamental prior') people tend to hold their prior belief even more fiercely (Edwards and Smith 1996). The tendency is to accept evidence that confirms one's prior opinion at face value while subjecting 'disconfirming' evidence to critical evaluation - the so-called 'disconfirmation bias' (Lord et al. 1979). Furthermore, the idea that attitudes and beliefs on any given subject are readily available in a 'mental file' that can be consulted and reported upon in a survey, the so-called file-drawer model (Wilson and Hodges 1992), has been widely criticised on the basis that multiple factors influence respondents' answers to attitude questions (Tourangeau et al. 2000). Our own study supports the notion that reading is not necessarily believing. When it comes to updating beliefs, the challenge for research communicators is to make a message clear, memorable and convincing so that all readers can recall and understand what they have read, even if they choose not to agree with it.

Finally, when it comes to actions, two particularly tenuous assumptions are immediately apparent: (1) that information which is read, understood, and absorbed will lead to action, and (2) that readers need to read, understand and absorb a message before they act. It is well understood that a number of contextual factors will influence a readers' tendency to translate information to action, even if they have engaged with and been convinced by a message. So those 
Figure 3 Readers may take alternative routes that could subvert a policy brief's effectiveness

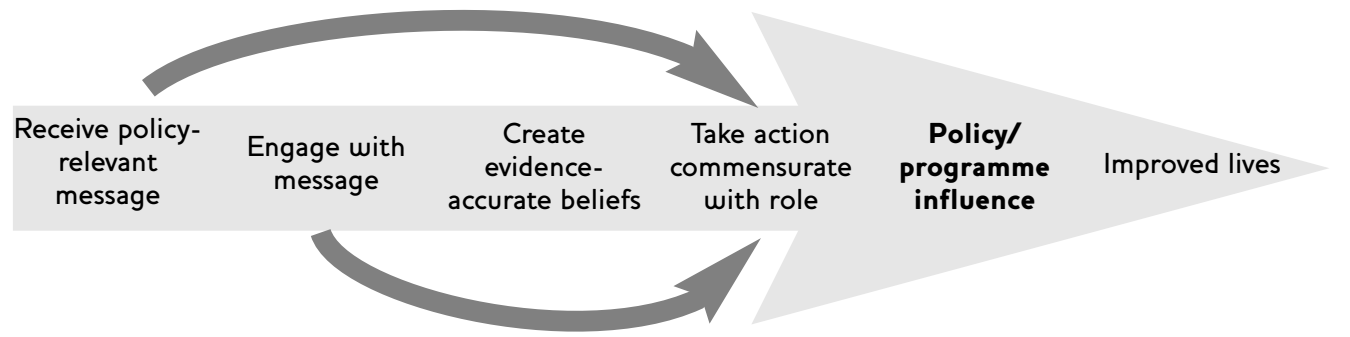

readers who do develop an evidence-accurate belief may still fail to act. Alternatively, readers who don't update their beliefs (either because they never engaged with the brief or because they consciously or unconsciously rejected the message) may succeed in taking action regardless - that is, they pass on the hot potato quickly and without first feasting on its goodness. Just as readers make quick decisions about whether or not they will read a brief themselves, they can also make quick decisions to send the brief on to others within their knowledge network. Likewise, readers who mistook the message of a brief could still succeed in taking any range of actions based on their misunderstanding, and those who rejected the message of a brief may be prompted to research further for example. Our own study findings do suggest that some readers move directly to action without fully internalising the message of the brief. Further challenges for research communicators therefore are to maximise the likelihood that a convinced reader will take action, perhaps through a strong call to action within a policy brief, and to maximise the likelihood that readers will share an accurate representation of the message in the brief, perhaps by making it easy for them to share the original brief rather than their interpretation of it.

So, we see that the mechanism through which a policy brief works is far from simple and linear. Instead, there are a number of alternative routes a reader can take from receipt to action or inaction, depicted in Figure 3, some of which could subvert the intended outcome of the policy brief in question.

\section{Finding 2 The Authority and Opinion affects influence actions but not beliefs}

The study found no significant Authority or Opinion affects on beliefs but some affect on intended and completed follow-up actions. In particular, (1) readers of the policy brief that includes an opinion piece by the sector expert and systematic review co-author, Lawrence Haddad, were more likely to have told someone about the key messages, and (2) readers of either policy brief that includes an opinion piece (attributed to Lawrence Haddad or to an unnamed author) were more likely to have sent the brief to someone else.

Furthermore, the study found that knowing the sector expert, Lawrence Haddad, strengthened both of these effects, but it did not take away the effect of the treatment, suggesting that it is the opinion itself rather than the Authority that is of greatest effect.

Study participants had mixed views about whether Haddad's authorship influenced their reading dependent on whether they were familiar with the author at all. In general, readers who have a closer relationship with the author or his work were more likely to perceive an Authority effect. This is not to say they were more likely to agree or change their beliefs but they did feel they were more likely to engage with the policy brief and recall its message. Perhaps the Authority effect is to make the brief more memorable which in turn leads to a greater likelihood of readers to share the message with someone else? These findings have implications for our understanding of what makes for an effective policy brief, to which we turn in Section 4. 


\section{What makes for an effective policy brief?}

Our own study found that a policy brief that gives personality and form to the researcher behind the written word did not increase its effectiveness for changing beliefs. But it did increase effectiveness in terms of the actions to share research the message. It could be that by including opinion and an authoritative source, an otherwise flat and impersonal policy brief can invoke a deeper relationship between the reader and the author, and by so doing affect their actions. The study findings suggest a complex and yet unresolved interaction between readers and just two of many variables in the design of a policy brief that could influence its effectiveness. While further research is required to unpack these effects further, at this stage it would seem advisable for those working in research communication to consider including such features within policy briefs they are preparing if they want readers to keep 'passing on the hot potato'.

\section{Notes}

1 'Pass the hot potato' is a party game in which players sit in a circle and toss a small object like a potato to other players while music is playing. When the music stops the person holding the object is disqualified and play continues until only one player is left. He or she is the winner and gets a prize - perhaps they can eat the hot potato. The analogy here is that like info-mediaries do with information, players pass on the object indiscriminately and with speed, taking little from it until the winner takes all.

2 'Policy brief' is variously defined by a multitude of authors and institutes, generally in 'how to' guidance notes. Guidance is often conflicting (e.g. advice as to whether the brief should be neutral or include opinions), and while most guidance agrees on general principles, no single format is proven to be best.

3 Policymaking is complex and the discussion of its complexity are well rehearsed elsewhere. We don't suppose that any researcher or communication expert would propose to bring about evidence-informed policy using a standalone policy brief and no other tools or plan for engagement.

4 A search of the term 'policy brief' returned no less than 30 million results in general Google and 2.8 million results in Google scholar.

\section{Passing on the hot potato}

In this article we have reflected on the mechanism and effectiveness of a policy brief as a standalone tool. In a 'real world' situation, few research organisations would rely on a policy brief alone to influence their key target audiences and would instead use a policy brief as one tool in a multipronged influencing approach. Nonetheless, the findings are relevant because most research organisations $d o$ put their policy briefs into the public domain on websites and in hardcopy where they can be (and are) read as a standalone resource by any interested actor. While they may be on the periphery of most influencing strategies, these actors are many and varied and they have potential to be influenced by research communication, and potential to go on to influence policy and practice in previously underexplored ways. Perhaps the next question to ask then is 'how does a policy brief perform as part of a sophisticated engagement strategy?' An interesting question that will no doubt be the focus of at least one policy brief in the future.

5 To the best of our knowledge, no such quantification has been undertaken, but it would not be excessive to estimate that the annual investment in policy briefs across the development sector would run into the millions of pounds.

6 A placebo is a neutral treatment that has no 'real' effect on the dependent variable - in this case for example on acquired knowledge on the topics covered in the treatment brief. The specific brief used in this study was Greeley and Gorman (2010).

7 The population was contacted by email and was compiled from three contact lists held by IDS' Knowledge Services Team. The study was further advertised through an open invitation posted on seven relevant communities of practice.

8 Based on qualitative interviews with a sample of participants. Also, one interviewee reported a very different reason for sharing the policy brief with 22 colleagues - because he thought the format was of interest. He explained 'The information was contained within a policy brief and we also write policy briefs. It was a good example on how to augment your arguments and make it strong'.

9 Some would argue that a policy brief is never intended to have influence in and of itself but rather as part of a package of engagement. In 
a recent blog discussion, Enrique Mendizabal describes a policy brief use as 'Something one leaves behind after a meeting (or sends in advance). It is what gets forwarded, etc. But

\section{References}

Beynon, P.; Chapoy, C.; Gaarder, M. and Masset, E. (2012) Full Report: What Difference does a Policy Brief Make?, Brighton: IDS

Cottle, G. (2011) Report on the Policy Community Survey, prepared for IDRC's Think Tank Initiative, Toronto ON: GlobeScan

Edwards, K. and Smith, E. (1996) 'A Disconfirmation Bias in the Evaluation of Arguments', Journal of Personality and Social Psychology 71.1: 5-24

Greeley, M. and Gorman, C. (2010) 'Priorities for Accelerating Progress on the MDGs', In Focus Policy Briefing, Brighton: IDS

Hovland, C. (1954) 'Effects of the Mass Media of Communication', in G. Lindzey (ed.), Handbook of Social Psychology, Vol 2, Cambridge MA: Addison-Wesley: 1062-103

Jones, N. and Walsh, C. (2008) Policy Briefs as a Communication Tool for Development Research, Background Note, London: Overseas Development Institute

Jones, N.; Jones, H. and Walsh, C. (2008) Science? Strengthening Science-policy Dialogue in does it influence on its own? Certainly not' http://onthinktanks.org/2012/03/30/shouldthink-tanks-write-policy-briefs-what-an-rctcan-tell-us/ (accessed 30 March 2012).

Developing Countries, ODI Working Paper 294, London: Overseas Development Institute

Lord, G.G.; Ross, L. and Lepper, M.R. (1979)

'Biased Assimilation and Attitude

Polarization: The Effects of Prior Theories on Subsequently Considered Evidence', Journal of Personality and Social Psychology 37.11: 2098-109

Masset, E.; Haddad, L.; Cornelius, A. and IsazaCastro, J. (2011) A Systematic Review of Agricultural Interventions that Aim to Improve Nutritional Status of Children, London: EPPICentre, Social Science Research Unit, Institute of Education, University of London ODI (2004) 'Bridging Research and Policy in International Development. An Analytical and Practical Framework', Briefing Paper, London: Overseas Development Institute

Tourangeau, R.; Rips, L.J. and Rasinski, K. (2000) The Psychology of Survey Response, Cambridge University Press

Wilson, T.D. and Hodges, S.D. (1992) 'Attitudes as Temporary Constructions', in L. Martin and A. Tesser (eds), The Construction of Social Judgment, Hillsdale NJ: Erlbaum: 37-65 